\title{
SOSIALISASI PROBLEM SOLVING KLAIM BPJS DI RUMAH SAKIT
}

\author{
Harris Rambey ${ }^{1}$, Irmayani ${ }^{1}$, Delita Br Panjaitan ${ }^{1}$, Arif Sudjatmiko ${ }^{1}$ \\ ${ }^{1}$ Program Studi Kesehatan Masyarakat Program Magister, \\ Institut Kesehatan Medistra Lubuk Pakam \\ JIn. Sudirman No.38 LubukPakam, Kabupaten Deli Serdang, \\ Sumatera Utara - Indonesia \\ *email korespondensi author: harisrambey@medistra.ac.id
}

DOI $10.35451 /$ jpk.v1i1.726

\begin{abstract}
Abstrak
Indonesia sebagai Negara kesejahteraan (welfare state) bertujuan untuk meningkatkan tingkat kenyamanan dan kesejahteraan bagi masyarakat umum. salah satu hal yang bisa meningkatkan derajat kesehatan adlah dengan memiliki jaminan kesehatan yang dapat digunakan pada saat melakuan perobatan. Pada praktiknya, pembentukan BPJS tidak sesuai dengan realita yang berjalan, dibuktikan dengan terdapatnya beragam permasalahan yang sulit untuk diatasi. Salah satunya adalah permasalahan dalam manajemen klaim BPJS. Adapun yang menjadi subjek penelitian ini adalah jaminan kesehatan, khususnya manajemen klaim. Penelitian ini menggunakan metode penelitian hukum normatif dengan pendekatan perundangundang, pendekatan konseptual, dan pendekatan kasus. Hasil penelitian menunjukkan bahwa meskipun telah ada upaya dari pemerintah dalam mewujudkan upaya penyelesaian masalah yang ada, namun upaya-upaya tersebut tidak berjalan efektif karena beberapa faktor penghambat. Diperlukan solusi berupa pembentukan dan penerapan konsep IMP (Identity Monitoring Program) yang terintegrasi dengan Disduk Capil dengan BPJS. Penerapan konsep IMP ini diharapkan dapat meminimalisir defisit pada jaminan Kesehatan dan menjadi solusi penyelesaian permasalahan manajemen klaim sebagai salah satu akar masalah dalam defisit BPJS.
\end{abstract}

Kata kunci: Identity Monitoring Program; Jaminan Kesehatan; Manajemen Klaim;

\begin{abstract}
Indonesia as a welfare state aims to increase the level of comfort and welfare for the general public. One of the things that can improve health status is to have health insurance that can be used when taking treatment. In practice, the formation of BPJS is not in accordance with the current reality, as evidenced by the existence of various problems that are difficult to overcome. One of them is the problem in BPJS claim management. The subject of this research is health insurance, especially claims management. This study uses a normative legal research method with a statutory approach, a conceptual approach, and a case approach. The results of the study indicate that although there have been efforts from the government in realizing efforts to solve existing problems, these efforts have not been effective due to several inhibiting factors. A solution is needed in the form of the formation and application of the IMP (Identity Monitoring Program) concept that is integrated with the Disduk Capil and BPJS. The implementation of the IMP concept is expected to minimize the deficit in health insurance and be a solution to the problem of solving claims management as one of the root causes of the BPJS deficit.
\end{abstract}

Keywords: Health Insurance; Identity Monitoring Program; Management of claims; 
Received: 07 June 2021 :: Accepted: 30 June 2021 :: Published: 30 Desember 2021

\section{Pendahuluan}

Perubahan di era globalisasi tentang pembiayaan kesehatan nasional oleh JKN (Jaminan Kesehatan Nasional) dalam hal di bidang Badan Penyelenggara Jamina Sosial) menuntut seluruh elemen penyelenggara pelayanan kesehatan menata kembali dalam upaya pelayana kesehatannya terkait dengan kendali mutu dan kendali biaya (Adrianto,2017)

Pembiayaan

kesehatan merupakan bagian yang penting dalam melakukan implementasi Jaminan Kesehatan Nasional (JKN). Dikembangkannya jaminan sosial oleh pemerintah suatu negara, termasuk Indonesia, tidak lain adalah untuk mengatasi permasalahan kesejahteraan pada masyarakat, yang akan berdampak sebagai hambatan pembangunan negara. Jaminan sosial merupakan salah satu bentuk upaya pemerintah negara kesejahteraan yang erat kaitannya dengan kebijakan sosial dalam meningkatkan kesejahteraan masyarakat (Putri, 2014).

Penyelenggaraan sistem jaminan sosial oleh pemerintah, bertujuan untuk memenuhi kebutuhan dasar hidup yang layak bagi masyarakat apabila terjadi hal-hal yang dapat mengakibatkan hilangnya atau berkurangnya pendapatan, karena menderita sakit, mengalami kecelakaan, kehilangan pekerjaan, memasuki usia lanjut, atau pension Undang-undang No 40 tahun 2004 mengenai sistem jaminan sosial nasional menyatakan bahwa prinsip pelaksanaan jaminan kesehatan nasional adalah kesetaraan dalam mendapatkan akses pelayanan kesehatan secara efektif dan efisien dalam melakukan operasionalisasinya, dalam prinsip kendali mutu dan biaya diterapkan secara utuh di setiap tingkatan pelayanan meningat adanya krakteristik pelayanan kesehatan yang berpotensi untuk menyebabkan terjadinya inefisiensi (Mudiyono, 2012)

Salah satu upaya yang telah disepakati seluruh pemangku kepentingan untuk dijalankan oleh BPJS Kesehatan adalah dengan melakukan penerapan model pembayaran prospektif, sesuai dengan undang-undang tentang sistem jaminan sosial nasional tahun 2004 no 40 (UU No 40, 2004)

Tujuan dilakukannya pembiayaan kesehatan adalah untuk mendorong peningkatan mutu, mendorong layanan berorintasi pada pasien sebagai pengguna, mendorong efisiebsi tidak melakukan pemberian reward terhadap provider yang melakuan over dalam hal pembiayaan. Salah satu upaya yang telah disepakati seluruh pemangku kepentingan untuk dijalankan oleh BPJS Kesehatan adalah melakukan penerapan model pembayaran prospektif. Agar sistem jaminan sosial nasional di Indonesia dapat terselenggara secara efektif, maka dibentuklah suatu lembaga yang berwenang menyelenggarakan pelayanan jaminan sosial, yakni Badan Penyelenggara Jaminan Sosial atau yang disingkat dengan BPJS (Kesmawan, 2014).

BPJS dibentuk berdasarkan Undang- Undang Nomor 24 Tahun 2011 tentang Badan Penyelenggara Jaminan Sosial (selanjunya disingkat UU BPJS). Salah satu bentuk jaminan sosial yang sangat dibutuhkan masyarakat saat ini adalah jaminan sosial kesehatan yang memiliki berbagai manfaat untuk menjamin pelayanan kesehatan secara menyeluruh, mulai dari peningkatan kesehatan (promotif), pencegahan penyakit (preventif), pengobatan penyakit (kuratif), dan pemulihan kesehatan (rehabilitatif), termasuk obat-obatan dan bahan medis habis pakai (Zulkahfi. 2014).

Salah satu permasalahan yang menjadi tantangan bagi pemerintah untuk segera diatasi, terkait penyelenggaraan jaminan kesehatan oleh BPJS adalah, adanya klaim oleh keluarga atau kerabat peserta BPJS Kesehatan yang telah meninggal namun memiliki ID peserta yang masih aktif. Dengan sistem pembiayaan yang tepat diharapkan mampu melakukan pembiayaan yang merata bagi semua kalangan. Dalam kegiatan pengabdian masyarakat ini permasalahan yang diangkat adalah perlunya upaya-upaya perubahan di Rumah sakit. 
Received: 07 June 2021 :: Accepted: 30 June 2021 :: Published: 30 Desember 2021

\section{Metode}

Dalam metode pengabdian masayarakat dilakukan dengan cara ceramah, diskusi, tanya jawab dan simulasi terkait tentang sistem pelayanan dalam bidang pembiayaan kesehatan dalam melakukan problem solving Klaim BPJS kesehatan di rumah sakit seperti:

1. Aksesibiltas, dalam upaya kemudahan bagi masyarakat dengan kesulitan ekonomi untuk mendapatkan fasilitas kesehatan maka mekanisme BPJS memberikan kemudahan bagi masyarakat dalam mengakses fasilitas kesehatan

2. Fasilitas, dalam upaya meningkatkan fasilitas fisik dan sarana prasarana menunjukkan adanya pengaruh positif.

3. Profesionalitas, dalam peran BPJS meningkatkan ketahanan masyarakat dalam bidang kesehatan yang dilakukan melalui upaya peningkatan profesionalisme dalam pelayanan kesehatan ditunjukkan melalui peningkatan pendidikan bagi pegawai rumah sakit.

4. Imunitas, peran BPJS dalam meningkatkan ketahanan kesehatan masyarakat bidang kesehatan dilakukan melalui upaya meningkatkan program promotif dan preventif.

\section{Hasil dan Pembahasan}

Kegiatan pemberdayaan kader BPJS Kesehatan dilaksanakan dalam beberapa tahap yaitu berupa 1) sosialisasi program, 2) persiapan pelatihan dan 3) pelaksanaan pelatihan serta dalam kegiatan ini disampaikan materi-materi terkait akreditasi RS terbaru, meliputi dasar hukum, standar-standar, paradigma baru yang perlu dipahami oleh segenap civitas hospital Rumah Sakit, serta proses persiapan yang perlu.

Terkait dengan permasalahan manajemen klaim yang dihadapi oleh BPJS Kesehatan, maka diperlukan suatu upaya penyelesaian yang relevan dan dapat mengakomodir permasalahan tersebut. sebagai Rumah
Sakit yang masih berkembang perlu dimulai dengan cara menata orientasi dalam membenahi manajemen dan pelayanannya, sehingga diharapkan mampu melakukan perbaikan dan peningkatan dan jaminan mutu pembiayaan kesehatan. Hal tersebut memungkinkan untuk menerapkan dasar dan standar-standar terbaik yang dapat dicapai disetiap Rumah Sakit sesuai dengan aturan yang berlaku dan ilmu pengetahuan serta teknologi terbaru.

Hal-hal tersebut di atas menuntut kerjasama dan kolaborasi yang sinergis dari segenap civitas hospitalia. serta seluruh staf harus diberikan bekal dan diberdayakan secara optimal agar dapat memenuhi.

Sosialisasi program dilakukan sebagai rangkaian kegiatan kader Klaim BPJS untuk terlibat langsung dengan pasien dan pimpinan dan memahami kondisi di lapangan. Kader klaim bpjs harus mampu mempelajari dan melakukan analisis mengenai masalah masyarakat terkait dengan status gizi dan terlibat aktif dalam program peningkatan pengetahuan dan keterampilan dalam melakukan problem solving atau pemecahan masalah di bagian klaim bpjs kesehatan, dimana dalam melakukan sosialisasi program dilakukan oleh pimpinan rumah sakit yang bertujuan untuk mendapatkan izin kegiatan di desa tersebut.

Kegiatan ini mencakup penentuan jadwal pelaksanaan dan mempersiapkan berbagai kebutuhan sarana pelatihan. Data yang didapatkan kemudian didiskusikan bersama narasumber dalam sebuah diskusi kelompok, sebuah organisasi nirlaba yang fokus dalam pengembangan upaya promotif dan preventif dibidang kesehatan dalam bidang pelayanan kesehatan. Didapatkan rancangan materi dan metode pelatihan yang dianggap paling sesuai dengan kondisi kader klaim bpjs kesehatan. 


\section{Problem-Solving}

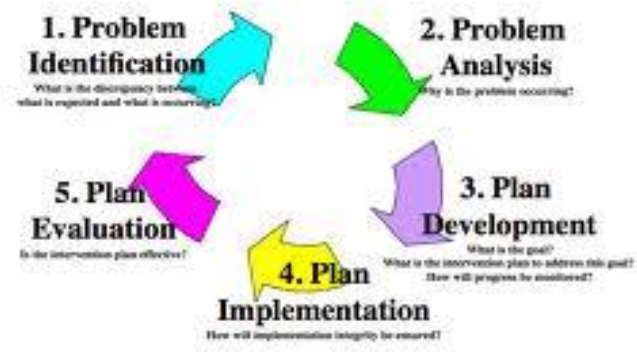

Gambar 1. Tahap pelaksanaan kegiatan Problem Solving

\section{Kesimpulan}

Berdasarkan hasil Pelatihan dalam pemberdayaan kader klaim bpjs sebagai kader pelayanan kesehatan merupakan salah satu kegiatan dari rangkaian pengabdian pada masyarakat yang terintegrasi yang
Dilaksanakan di bagian klaim bpks yanh ada di rumah sakit yang dihadiri oleh 25 kader. Proses pemilihan kader peserta pelatihan ditentukan oleh ketua atau koordinator kader disetiap bagian klaim bpjs, dengan kriteria utama adalah kader yang aktif dalam kegiatan pelayanan kesehatan. Kegiatan pelatihan dilaksanakan dalam tiga tahap yaitu sosialisasi program, persiapan pelatihan dan pelaksanaan pelatihan. Pelatihan dilakukan dengan menggunakan pendekatan model deduktif, materi pelatihan dibuat sama secara umum, disusun berdasarkan data pengamatan yang dilakukan oleh tim pengabdian masyarakat kemudian didiskusikan dengan narasumber ahli. sehingga peningkatan pengatahuan dan keterampilan dapat terasah terus.

Tabel 2. Manfaat program implementasi Klaim bpjs bagi masyarkat dan pemerintah

NO Pemerintah Masyarakat

1 Meningkatkan efisiensi dan efektifitas kinerja pelayanan oleh pemerintah.

2 Sebagai salah satu upaya pemerintah dalam mengatasi akar masalah defisit BPJS Kesehatan.

3 Mengefisienkan administrasi penonaktifan

waktu pengurusan kematian serta Kesehatan.

4 Mempermudah proses pelayanan BPJS Kesehatan bagi masyarakat.
Memudahkan masyarakat dalam mengurus administrasi kematian.

Memangkas biaya pengurusa berkas administrasi kematian maupun penonaktifan peserta BPJS Kesehatan.

Mendorong kelancaran pemberdayaan ekonomi masyarakat.

Mengefisienkan waktu masyarakat dalam mengurus administrasi kematian serta penonaktifan peserta BPJS Kesehatan.

\section{Ucapan Terima Kasih}

Pada kegiatan ini Pengabdian masyarakat mengucapkan trima kasih kepada seluruh pihak BPJS dan Rumah Sakit GrandMed, sehingga bisa terselenggara sebagai bagian dari Pemberdayaan bagi para kader klaim bpjs kesehatan yang ada di rumah sakit.

\section{Daftar Pustaka}

Arianto, B. 2017, "Menakar Keberhasilan Penyelenggaraan Jaminan Sosial", Jurnal Institut BPJS Ketenagakerjaan., Vol.2, No.1, November.

Mudiyono. 2012. "Jaminan Sosial Di Indonesia, Relevansi Pendekatan Informal". Jurnal. Ilmu Sosial Dan Ilmu Politik, Vol. 6, No.1.

Putri,2014. Paham JKN (Jaminan Kesehatan Nasional). Seri Buku 4. 
Received: 07 June 2021 :: Accepted: 30 June 2021 :: Published: 30 Desember 2021

Jakarta: CV Komunitas Pejaten Mediatama.

Undang-Undang Nomor 40 Tahun 2004 Tentang Sistem Jaminan Sosial Nasional.

Zulkahfi. 2014. "Jaminan Kesehatan Nasional (JKN) Dalam Perspektif Hukum Islam", Skripsi. Yogyakarta: UIN Sunan Kalijaga.

Kesmawan, A. P. \& Mutiarin, D. 2014, "Implementasi Kebijakan Badan Penyelenggara Jaminan Sosial (BPJS) Kesehatan di Kabupaten Bantul Daerah Istimewa 